\title{
Presencia de indicadores microbiológicos en agua para consumo humano en San Cosme (Corrientes, Argentina)
}

\author{
Rodríguez, S.C.'; Asmundis, C.L. ${ }^{1}$; Ayala, M.T. ${ }^{2}$; Arzú, O.R. ${ }^{2}$ \\ ${ }^{1}$ Facultad de Ciencias Agrarias, ${ }^{2}$ Facultad de Ciencias Veterinarias, Universidad \\ Nacional del Nordeste, Sargento Cabral 2139, Corrientes (3400), Argentina. \\ E-mail: silvicarlo@yahoo.com.ar
}

\begin{abstract}
Resumen
Rodríguez, S.C.; Asmundis, C.L.; Ayala, M.T.; Arzú, O.R.: Presencia de indicadores microbiológicos en agua para consumo humano en San Cosme (Corrientes, Argentina). Rev. vet. 29: 1, 9-12, 2018. El agua destinada al consumo humano no debe contener ningún agente patógeno, siendo necesario realizar análisis para determinar microorganismos indicadores de contaminación. Así, bacterias coliformes fecales informan contaminación fecal y Pseudomonas aeruginosa señala deterioro o recontaminación del agua. Con el objeto de establecer la presencia de tales indicadores en una zona rural y evaluar la calidad microbiológica del agua para consumo humano, se investigaron dos tipos diferentes de fuentes de agua, una subterránea (pozo y perforación) y otra superficial (laguna). Las muestras colectadas en frascos estériles se mantuvieron refrigeradas a $4-6^{\circ} \mathrm{C}$, determinándose la cantidad presuntiva de coliformes totales en series de cinco tubos de caldo MacConkey y confirmación de positivos con caldo brila a $37^{\circ} \mathrm{C}$. La confirmación de la presencia de coliformes fecales y $P$. aeruginosa se efectuó usando el medio selectivo que contiene cristal violeta a $37^{\circ} \mathrm{C}$, repicando en agar cetrimide a $37^{\circ} \mathrm{C}$. En los pozos se registraron los valores más altos de contaminación por coliformes fecales, siendo la perforación la fuente de agua de menor riesgo de polución. En cuanto a $P$. aeruginosa, su presencia se constató en las tres fuentes de agua, en distintos períodos de tiempo, siendo el agua de laguna la que presentó mayor contaminación. De acuerdo al Código Alimentario Argentino, estos resultados muestran la ineptitud para el consumo de las aguas analizadas.
\end{abstract}

Palabras clave: agua, calidad, consumo humano, contaminación bacteriana, coliformes fecales, Pseudomonas aeruginosa.

\begin{abstract}
Rodríguez, S.C.; Asmundis, C.L.; Ayala, M.T.; Arzú, O.R.: Microbiological presence indicators of water for human consumption in San Cosme (Corrientes, Argentina). Rev. vet. 29: 1, 9-12, 2018. Water for consumption should not contain any pathogen, it is necessary to analyze to determine contamination indicator microorganisms. Fecal coliform bacteria indicate fecal contamination and deterioration. Pseudomonas aeruginosa pointing deterioration or re-contamination of the water. In order to establish the presence of these indicators of contamination and assess the microbiological quality of water for human consumption, we worked with two different types of water sources: groundwater (well and drilling) and shallow (lagoon). Samples collected in sterile bottles were kept refrigerated at $4-6^{\circ} \mathrm{C}$, determined the most probable number of total coliforms in presumptive phase by the series of five tubes of broth MacConkey and confirmation of positive broth at $37^{\circ} \mathrm{C}$ brila; presence of fecal coliforms from presumptive positives total coliforms phase, and the presence of $P$. aeruginosa using selective medium containing crystal violet at $37^{\circ} \mathrm{C}$, cetrimide agar pealing at $37^{\circ} \mathrm{C}$. In wells with higher values of contamination by fecal coliforms it was recorded, with drilling water source lower risk of contamination. As for $P$. aeruginosa his presence was recorded in the three water sources, in different periods of time, being the lagoon water source showed higher contamination. According to the Argentine Food Code, these results show the unfitness for consumption of the analyzed waters.
\end{abstract}

Key words: water, quality, human consumption, bacterial contamination, fecal coliforms, Pseudomonas aeruginosa. 


\section{INTRODUCCIÓN}

La salud de un ecosistema acuático es esencial y no depende solo de la cantidad de agua, sino de su cali$\mathrm{dad}^{4}$. Los procedimientos para el monitoreo de la calidad del agua requieren una evaluación microbiológica mediante el uso de organismos indicadores, como son las bacterias coliformes totales o fecales ${ }^{3}$. El grupo de tales microrganismos se aplica como prueba general de monitoreo de calidad del agua. Esto provee información importante sobre la fuente y el tipo de contaminación presente ${ }^{11}$.

En el grupo de coliformes totales están incluidos los bacilos Gram negativos, no formadores de esporas, que fermentan la lactosa con producción de gas dentro de las 48 horas a $35^{\circ} \mathrm{C}$. Están siempre presentes en la flora intestinal y aunque algunas especies están ampliamente distribuidas en la naturaleza, su presencia indica tratamiento inadecuado del agua o su contaminación posterior.

Por otro lado se definen a los gérmenes coliformes fecales como aquéllos capaces de fermentar la lactosa, con producción de gas, dentro de las 24 horas a $44,5^{\circ} \mathrm{C}$. Esto indica un riesgo potencial para la salud pública por contaminación fecal y tales características son aprovechadas para cuantificar estas bacterias ${ }^{8}$.

Como bacteria indicadora de contaminación fecal en agua se utiliza también Pseudomonas aeruginosa. Es un contaminante normal de aguas de pozos que no han pasado por un proceso de potabilización ${ }^{7}$. Se la asocia a residuos fecales humanos más que a heces de animales.

$P$. aeruginosa está reportada como la de mayor importancia clínica dentro de los bacilos Gram negativos no fermentadores, pues además de ser uno de los principales responsables de infecciones intrahospitalarias también es causante de epidemias severas de diarreas en lactantes ${ }^{10} \mathrm{y}$ en enfermos hospitalizados. Todas sus cepas son potencialmente patógenas para el hombre, dada su producción de compuestos tóxicos.

En ambientes acuosos este microorganismo se adhiere fácilmente a superficies inertes de diferentes materiales formando biopelículas que facilitan su establecimiento y que son producto de la expresión de genes específicos que codifican para proteínas que sintetizan moléculas señales para la unión célula-célula y el inicio de la síntesis de polisacáridos. A su vez esta biopelícula constituye una protección contra la cloración, y es por ello que se considera un indicador de eficiencia del tratamiento ${ }^{14}$.

El Código Alimentario Argentino establece que debe haber ausencia tanto de coliformes fecales como de $P$. aeruginosa por $100 \mathrm{ml}$ de agua para que sea apta para el consumo humano ${ }^{2}$.

El objetivo del presente trabajo fue evaluar la calidad microbiana del agua de consumo humano provenientes de distintas fuentes en chacras de pequeños productores de la localidad de San Cosme, Provincia de Corrientes (Argentina), a lo largo de un año durante las cuatro esta- ciones, estableciendo la presencia de indicadores microbiológicos de contaminación, así como correlacionando la presencia de tales indicadores con la aptitud del agua, acorde a los valores de referencia de calidad del Código Alimentario Argentino (Ley 18.284).

\section{MATERIAL Y MÉTODOS}

Para la investigación se seleccionaron 12 muestras de cada una de las fuentes de agua de consumo humano provenientes de agua superficial (laguna) y subterránea (perforación, pozos profundos y pozos a balde), con cuatro repeticiones para cada fuente.

Los muestreos tuvieron una periodicidad trimestral, con el fin de obtener parámetros estacionales durante un año (verano, otoño, invierno, primavera). Conjuntamente con la extracción de las muestras de agua se tomaron los datos de temperatura y hora de extracción, como así también la ubicación de los pozos negros y/o aguadas para evaluar las condiciones higiénicas de las fuentes de extracción de agua.

Los instrumentos utilizados en los muestreos para análisis bacteriológico fueron: envases (frascos de plástico, con tapa hermética, boca ancha y esterilizados, con capacidad de 250-300 ml), conservadora, alcohol $70^{\circ}$, guantes, gel-pack (o hielo), hisopos de algodón, pinzas de brazos largos, fósforos, cinta para rotular, marcador indeleble y planillas de registro.

Para la extracción de las muestras de agua de perforación, se eligió un grifo que estuviera conectado directamente con la cañería de distribución, el cual se desinfectó con un hisopo de algodón embebido en alcohol en combustión, calentándolo por varios minutos. Se abrió la llave y se dejó correr agua por lo menos por 30 segundos, de forma tal que el chorro no fuera intenso. Luego se abrió la tapa del envase estéril, evitando todo contacto de los dedos con la boca del mismo y se lo llenó con el agua a analizar, a un centímetro por debajo de la boca del recipiente.

Para el agua de pozo, el balde se lavó perfectamente, interior y exteriormente, para que no quedara tierra ni basura. En el interior del mismo se volcó el contenido de un vaso de alcohol de quemar y se encendió. Mientras ardía se hizo correr el alcohol incendiando las paredes del balde, al efecto de esterilizar totalmente la superficie interna. El balde se apoyó sobre una superficie limpia. La parte externa del balde se esterilizó con un hisopo embebido en alcohol.

Cuando se concluyó con las operaciones de esterilización se ató una soga limpia al balde y se lo sumergió en el pozo rápidamente. Se llenó el balde y se lo elevó hasta la superficie. Parte de su contenido se vertió directamente al envase, hasta $1 \mathrm{~cm}$ por debajo de la boca del recipiente. Luego se tapó.

Para recolectar agua de laguna, el envase se tomó por el cuello mediante una pinza de brazos largos esterilizados, sumergiéndolo rápidamente hasta unos $20 \mathrm{~cm}$ por debajo de la superficie del agua. Una vez llenado el envase, se levantó rápidamente y se lo tapó. En todos los 
casos de toma de muestras y cualquiera fuera la fuente de agua, se utilizaron guantes para no alterar las mismas.

Respecto al método de conservación, es dable destacar que cuando se conserva una muestra bacteriológica, se espera que el método a utilizar respete el número de células microbianas sin dañar su metabolismo. Por ello se mantiene una temperatura en la cual se retrasan sus funciones metabólicas o incluso se detienen, sin causarles la muerte ${ }^{9}$.

Las muestras fueron colectadas en frascos estériles, se mantuvieron refrigeradas a $4-6^{\circ} \mathrm{C}$, siendo transportadas al laboratorio antes de las $24 \mathrm{~h}$ de su recolección ${ }^{10}$. Una vez en el laboratorio se procedió a su procesamiento dentro de las 2 horas subsiguientes.

Los análisis bacteriológicos se realizaron acorde a la metodología propuesta por la American Water Works Association \& Water Pollution Control Federation (standard methods for the examination of water and wastewater) ${ }^{1}$. Así, el "Número Más Probable" (NMP) de coliformes totales se estimó según una fase presuntiva por la serie de cinco tubos de caldo McConkey y la confirmación de positivos con caldo brila a $37^{\circ} \mathrm{C}$.

La presencia de coliformes fecales se evaluó a partir de los positivos de la fase presuntiva de coliformes totales. La presencia de $P$. aeruginosa se evidenció a partir de un medio selectivo que contenía cristal violeta a $37^{\circ} \mathrm{C}$, luego repicado en agar cetrimide a $37^{\circ} \mathrm{C}$, medio selectivo y diferencial utilizado para el aislamiento y la identificación de dicho germen.

\section{RESULTADOS}

Bacterias coliformes fecales. En agua de pozo, la cantidad de NMP de coliformes fecales varió según los distintos puntos de muestreo y entre las diferentes fechas de toma de muestra. El mayor valor registrado fue en primavera (cuarto muestreo), en todos los puntos de muestreos (Figura 1).

En relación al agua de perforación, se observó que en algunos muestreos, no hubo registro de presencia de bacterias coliformes fecales (Figura 2).

De acuerdo al resultado de los análisis de las muestras de agua de laguna, se advirtió gran variabilidad de la presencia de coliformes en todo el periodo de estudio, incrementándose notoriamente en el tercer y cuarto muestreo (Figura 3).

Bacteria P. aeruginosa. En relación a las distintas fuentes, la presencia de $P$. aeruginosa registró comportamientos similares en agua subterránea (pozo y perforación), sin embargo esta presencia fue superior en agua superficial, de laguna (Figura 4). Esta diferencia se podría atribuir al arrastre de agua de lluvia hacia la fuente de agua.

\section{DISCUSIÓN}

Los valores de coliformes fecales presentaron una variación en el tiempo, existiendo diferencias significativas entre los muestreos. Como puede observarse, en

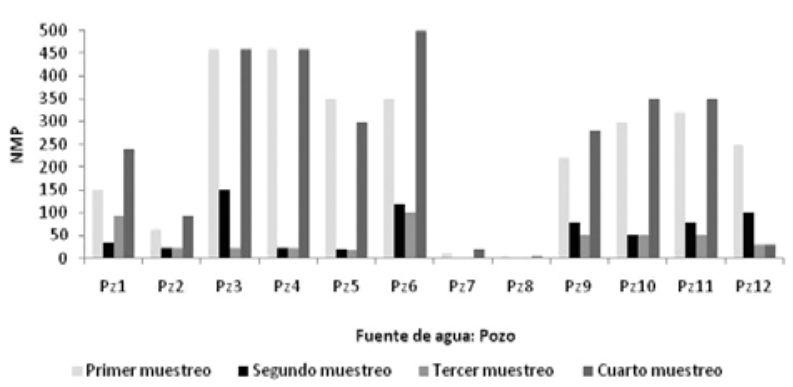

Figura 1. Número más probable (NMP) de coliformes fecales en agua de pozo.

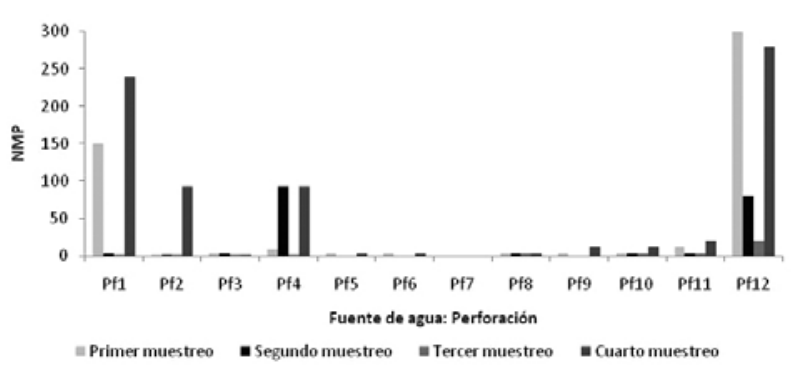

Figura 2. Número más probable (NMP) de coliformes fecales en agua de perforación.

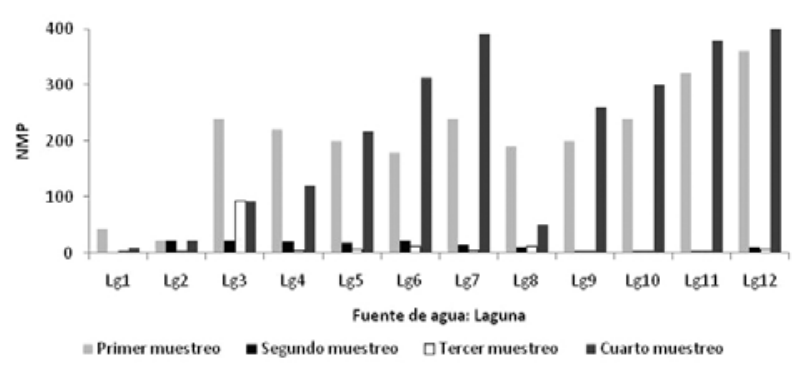

Figura 3. Número más probable (NMP) de coliformes fecales en agua de laguna.
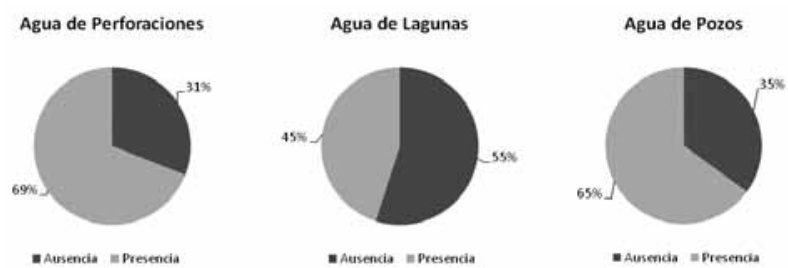

Figura 4. Presencia de P. aeruginosa en las distintas fuentes de agua.

el cuarto muestreo la abundancia de coliformes fue notoria en todos los casos, en coincidencia con períodos de lluvia abundante.

Estos resultados coinciden con los de investigadores que demostraron que la contaminación por coliformes en aguas para consumo está relacionada a la duración de la precipitación en los días que preceden al muestreo ${ }^{12}$. En otro trabajo se demostró que el recuento de coliformes fecales en aguas de baño permanecía elevado después de una lluvia de $5 \mathrm{~mm}$ o más, durante 2 a 5 días ${ }^{6}$.

En virtud de las observaciones de cada una de las fuentes en relación a la cantidad de bacterias colifor- 
mes, el pozo presenta una mayor exposición a la contaminación de estas bacterias, posiblemente por mal funcionamiento o daño del reservorio (infiltración, defecto de construcción), así como alguna comunicación entre esta fuente de agua y alguna contaminación permanente (pozo ciego, letrina, corrales).

Los defectos en la construcción y estructura de pozos y depósitos, así como la ausencia o irregular mantenimiento de dichas instalaciones, son causas que predisponen el ingreso y proliferación de microorganismos desde distintas fuentes ${ }^{5}$. También puede deberse a las malas condiciones sanitarias de mantenimiento y de la contaminación de la napa freática o acuífero libre. En nuestra experiencia, la perforación fue la fuente que presentó menor riesgo de contaminación bacteriana. En agua de laguna el problema radicaría en el agua de arrastre que alimenta esta fuente.

En algunos casos se detectó presencia de $P$. aeruginosa, dando negativo el recuento de coliformes fecales, lo que no significa que al no encontrarse estas bacterias, el consumo de esta agua no implique riesgo alguno, ya que $P$. aeruginosa tiene la capacidad de inhibir los coliformes ${ }^{13}$. La ausencia de bacterias coliformes en las muestras de agua de cisterna y tanques, no significa la ausencia de riesgo microbiológico, pudiéndose encontrar $P$. aeruginosa como patógeno oportunista.

Por ello, en las muestras se hace necesario realizar análisis para detectar tal bacteria y establecer si el agua es apta para el consumo. La presencia de coliformes totales y/o fecales no implica la existencia de $P$. aeruginosa y -por el contrario- la presencia de esta última no indica la existencia de coliformes, ya que $P$. aeruginosa es de origen fecal humano, a diferencia de las coliformes que pueden tener diferentes orígenes.

De acuerdo al Código Alimentario Argentino ${ }^{2}$, los resultados obtenidos en las chacras de pequeños productores examinadas en San Cosme (Corrientes, Argentina), demuestran la inaptitud de las aguas superficiales y subterráneas para el consumo humano.

\section{REFERENCIAS}

1. American Public Health Association, American Water Works Association \& Water Pollution Control Federation. 2005. Standard Methods for the Examination of Water and Wastewater, $21^{\text {th }}$ ed., Washington DC.

2. Código Alimentario Argentino. 2007. Artículo 982, Resolución 8/2007 y 196/2007. Modificación Ley 18.284. Decreto Reglamentario 2126, Capítulo XII: 1, Buenos Aires, Argentina.
3. Cook KL, Bolster CH. 2007. Survival of Campylobacter jejuni and Escherichia coli in groundwater during prolonged starvation at low temperatures. J Appl Microbiol 103: 573-583.

4. Díaz DC, Esteller AM, López VM. 2005. Recursos hídricos: conceptos básicos y estudios de casos en Ibero América. Ilustraciones, figuras, cuadros y gráficos, Ediciones Cirauaem, Toluca, México, p. 747.

5. Goya AB, Wilde OR. 1997. Calidad bacteriológica de las aguas en plantas faenadotas de la Provincia de Tucumán. Publ.Laboratorio Regional-GELAB-SENASA.

6. Harding W. 1992. Faecal coliform densities and water quality criteria in three coastal recreational lakes in the SW Cape, South Africa. Water SA 19: 235-246.

7. Lösch LS, Merino LA, Alonso JM. 2005. Resistencia antimicrobiana en cepas de Pseudomonas aeruginosa aisladas de fuentes de agua de la Provincia del Chaco (Argentina). Comunicaciones Cientificas y Tecnológicas., Instituto de Medicina Regional UNNE, Corrientes, Argentina, Resumen: M-014.

8. Madigan MT, Martinko JM, Parker J. 2009. Brock. Biología de los microorganismos, $11^{\text {va }}$ ed., Editorial Pearson Prentice Hall, Madrid, España.

9. Méndez RI, San Pedro L, Castillo ER, Vázquez E. 2010. Modelación del tiempo de conservación de muestras biológicas de agua. Rev Intern Contamin Ambient 26: 327-335.

10. Rose JB, Grimes DJ. 2001. Reevaluation of microbial water quality: powerful new tools for detection and risk assessment. A report from the American Academy of Microbiology. Am Soc Microbiol, Washington, DC, ADA392435.

11. Silva J, Ramírez L, Alfieri A, Rivas G, Sánchez M. 2004. Determinación de microorganismos indicadores de calidad sanitaria: coliformes totales, coliformes fecales y aerobios mesófilos en agua potable envasada y distribuida en San Diego, Estado Carabobo, Venezuela. Rev Soc Venez Microbiol 24: 46-49.

12. Stukel T, Greenberg R, Bradley D, Reed F, Jacobs N. 1990. A longitudinal study of rainfall and coliform contamination in small community water supplies. Environ Sci \& Technol 24: 571-575.

13. Torres Y. 1991. Utilización de Pseudomonas aeruginosa como indicador de contaminación en el agua de tanques y cisternas. Boletín de Lima 78: 27-28.

14. World Health Organization. 2011. Guidelines for drinking-water quality, $4^{\text {th }}$ ed., Geneva, Switzerland, 564 p. 